doi.org/10.51891/rease.v7i5.1223

\title{
CÂNCER INFANTIL: O IMPACTO DO DIAGNÓSTICO PARA A CRIANÇA E FAMILIARES
}

\author{
CHILDHOOD CANCER: THE IMPACT OF DIAGNOSIS FOR CHILDREN AND \\ FAMILIES
}

Leidiane Silva de Oliveira ${ }^{1}$

RESUMO: O câncer infantil corresponde a várias doenças. A característica comum dessa doença é a proliferação descontrolada de células anormais. Essa doença pode ocorrer em qualquer parte do corpo. Estima-se que 70\% das crianças com câncer podem ser curadas se diagnosticadas precocemente e tratadas corretamente. No centro, a maioria das pessoas tem boa qualidade de vida após o tratamento. A diferença entre o câncer adulto e o infantil é que a infância geralmente afeta as células do sistema sanguíneo e os tecidos de suporte. Métodos: O presente estudo trata-se de uma pesquisa bibliográfica, cuja trajetória metodológica percorrida apoiou-se nas literaturas exploratórias e seletivas do material de pesquisa, bem como em sua revisão integrativa, que contribui para o processo de síntese e análise dos resultados de vários estudos. Resultados: Posteriormente, o diagnóstico dessa mudança passou a ocorrer em todas as direções, caracterizando-se por um período em que ambos os lados foram rejeitados. Conclusão: Após este estudo pode-se dizer que o câncer é uma doença que acarreta muitas repercussões tanto na vida da pessoa que adoece quanto na dos familiares que acompanham o processo desde o diagnóstico, passando pelo tratamento e recuperação dos casos, requerendo desta forma uma forte atuação da equipe multiprofissional de saúde em relação à avaliação e todo suporte à pessoa e sua família. O diagnóstico do câncer infantil causa dor, ansiedade e inúmeras variedades de sentimentos. Passar por esse processo é doloroso e envolve muito medo e ansiedade, momentos muito delicados para a criança e sua família.

Palavras-Chave: Câncer. Enfermagem. Diagnóstico.

ABSTRACT: Childhood cancer corresponds to several diseases. The common feature of this disease is the uncontrolled proliferation of abnormal cells. This disease can occur anywhere in the body. It is estimated that $70 \%$ of children with cancer can be cured if diagnosed early and treated correctly. At the center, most people have a good quality of life after treatment. The difference between adult and childhood cancer is that childhood usually affects blood cells and supporting tissues. Methods: The present study is a bibliographic research, whose methodological path was based on the exploratory and selective literature of the researched material, as well as on its integrative review, which

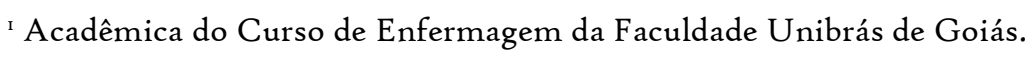


contributes to the process of synthesis and analysis of the results of several studies. Results: Subsequently, the diagnosis of this change started to occur in all directions, characterized by a period in which both sides were rejected. Conclusion: After this study, it can be said that cancer is a disease that has numerous repercussions both in the life of the person who falls ill, and in that of family members who accompany the process since the diagnosis, through the treatment and recovery of. the cases, thus requiring a strong performance of the multiprofessional health team in relation to the evaluation and all support to the person and his family. The diagnosis of childhood cancer causes pain, anxiety and innumerable varieties of feelings. Going through this process is painful and involves a lot of fear and anxiety, very delicate moments for the child and his family.

Keywords: Cancer. Nursing. Diagnosis.

\section{INTRODUÇÃO}

O Instituto Nacional de Câncer (INCA) (2015), entende o câncer como uma doença que acomete o corpo a partir do crescimento desordenado de células que invadem os tecidos e órgãos. Existem mais de ioo tipos de câncer e suas causas são variadas. Considerada u ma enfermidade crônica que ameaça a vida e também simboliza perigo desconhecido, sofrimento, dor e culpa, o câncer está associado ao risco iminente de morte.

Segundo Brasil (2008), há alguns anos que o câncer se transformou em um problema de saúde pública em âmbito mundial. Os números de diagnóstico de câncer são altos, e, dentro desses números, encontra-se a porcentagem específica do câncer infantil. O câncer infantil deve ser estudado a parte das ocorrências de câncer em adultos devido a essa diferença de origens histológicas - a maioria dos tumores em crianças apresenta achados histológicos que se assemelham a tecidos fetais, nos locais primários e de comportamentos clínicos. Por ser grande a diversidade morfológica resultante das transformações celulares constantes as classificações dos tumores pediátricos diferem das utilizadas nos adultos, sendo que a morfologia é o principal aspecto considerado.

A diferença entre o câncer de adulto e o câncer infantil, é que o infantil normalmente afeta as células do sistema sanguíneo e os tecidos de sustentação, já no adulto afeta as células do epitélio, que recobre os diferentes órgãos, como no caso do câncer de mama e no câncer de pulmão. As doenças malignas da infância, por serem predominantemente de natureza embrionária, são constituídas por células indiferenciadas, o que normalmente determina uma melhor resposta aos métodos terapêuticos atuais. Enquanto no adulto, muitas vezes, existe uma clara associação entre o surgimento do câncer e os fatores ambientais como, por exemplo, o uso do tabaco e o câncer de pulmão (BRASIL, 2008).

Cordoba et al. (2017), listaram que depois da revisão de alguns dados epidemiológicos e clínicos, as principais doenças oncológicas pediátricas são: Leucemias, Tumores do Sistema Nervoso Central, Linfomas, Tumor de Wilms, Neuroblastoma, Retinoblastoma, Tumores Ósseos Primários, Tumores de partes moles, Tumores do córtex supra-adrenal, Tumores hepáticos, Tumores ovarianos e Neoplasias malignas nos neonatos.

O câncer infantil "corresponde a um grupo de várias doenças que têm em comum a proliferação descontrolada de células anormais e que pode ocorrer em qualquer local do 
organismo". Estima-se que $70 \%$ das crianças com câncer podem ser curadas se diagnosticadas precocemente e tratadas adequadamente, em centros especializados, tendo a maioria uma boa qualidade de vida após o tratamento (BRASIL, 2008).

Tanto em países desenvolvidos, como no Brasil, o câncer já representa a segunda causa de mortalidade proporcional em crianças e adolescentes de i a I9 anos. Já que a primeira causa de morte esta associada aos fatores externos, tais como acidentes e violência, pode-se dizer que o câncer é a primeira causa de morte por doença a partir do primeiro ano de vida até o fim da adolescência. (BRASIL, 2008).

E apesar das chances de cura serem altas e muito eficientes caso o diagnóstico seja precoce, o espectro da morte iminente acompanha a criança com câncer (FERNANDES; SOUZA, 2019). Como as situações que caracterizam o tratamento do câncer infantil envolvem também a família/responsáveis legais, toda a estrutura familiar acaba por se ajustar ao processo que começa no diagnóstico e termina na cura ou na morte da criança (CAPRINI; MOTTA, 2017).

A própria comunicação do diagnóstico de câncer nos/as filhos/as, segundo Valle e Ramalho (2008), provoca grandes mudanças em toda a família. A vida de uma criança é totalmente modificada e alterada em diversos aspectos, causando-lhe, assim, o início de experiências muito sofridas, que podem gerar as mais diversificadas emoções. $O$ sofrimento gerado conduz a uma problemática psíquica, que desencadeia processos emocionais frágeis, os quais, nesses casos, exigem o acompanhamento de profissionais especializados durante o processo do tratamento (CARVALHO, 2002).

Segundo Alves et al. (2016), a partir do momento em que os familiares têm a confirmação do diagnóstico de câncer infantil, eles se veem frente ao novo e ao desconhecido, obrigando-os a buscar conhecimento para ter subsídios que lhes possibilitem lutar contra o adoecimento da criança. Durante o tratamento, a família passa por diversas mudanças e, mesmo com a ruptura do planejamento familiar, passa também a valorizar a vida e a união, tendo, na maioria dos casos, a religiosidade e a fé presentes como fatores de proteção, almejando, assim, o melhor desfecho para a vida da criança enferma.

Como o tratamento da criança com câncer deve ser abrangente, exigindo atenção às necessidades físicas, psicológicas e sociais. Além da inclusão da família, busca pela personalização da assistência, promoção de cuidados atraumáticos, garantia do direito à informação, e promoção da autoestima de todos que vivem esse processo deve-se: disponibilizar à criança informações sobre a doença e o tratamento; prepará-la para receber os procedimentos; adotar medidas para o alívio da dor e desconforto; incluir a família no processo de cuidado e garantir a tomada de decisão da família, da criança e do adolescente (LEMOS, LIMA e MELLO 2004).

Afim de contribuir na vivência dos profissionais da área da saúde e possibilitar um olhar mais humanizado e acolhedor favorecendo a relação Enfermeiro-Paciente no momento do diagnóstico de câncer infantil recebido pelos familiares e pela própria criança, Este estudo tem como objetivo Descrever o impacto que o diagnóstico do câncer infantil gera tanto na criança quanto nos familiares.

O adoecimento da criança e a hospitalização mudaram os hábitos de vida de toda a família, pois além de os pais terem que lidar com a doença, também precisam saber como lidar com os problemas financeiros. 
Como muitas famílias precisam deixar o trabalho para acompanhar os filhos durante o processo de adoecimento, gastam com transporte e hospedagem e, em alguns casos, não têm onde conseguir. Mesmo assim, ainda tentam ficar perto dos filhos porque têm medo de que algo aconteça caso eles escapem. Portanto, a família assume um novo papel, que visa proporcionar condições para que os filhos mantenham e desenvolvam seu potencial de sobrevivência.

A vivência dos fatores familiares na hospitalização gerou no cotidiano e na confusão dolorosa vivenciaram interrupções na vida familiar, principalmente no ambiente familiar, além das atividades financeiras e das necessidades de hospitalização, também assumiram responsabilidades anteriores.

\section{DISCUSSÃO}

O câncer é considerado um problema de Saúde Pública, conhecida como uma doença crônica degenerativa marcada por um crescimento desordenado e invasivo celular. De modo geral afeta a população com uma estimativa de $80 \%$ e de mais de 20 milhões de casos novos para o ano de 2025 (PAULA et al., 2019).

De acordo com o INCA (2018), "Câncer é o nome dado a um conjunto de mais de Ioo doenças que têm em comum o crescimento desordenado (maligno) de células que invadem os tecidos e órgãos, podendo espalhar-se (metástase) para outras regiões do corpo".

O câncer não possui uma idade predeterminada para se desenvolver, crianças também desenvolvem a doença. $O$ "câncer infantil" é um termo genérico que se refere a "[...] um grupo heterogêneo de doenças que apresentam taxas de morbi-mortalidade, que dependem do tipo e da extensão da doença, da idade da criança e da efetividade da resposta inicial do tratamento[...]" (RIBEIRO, 1994, p. 210).

Conforme o Instituto Oncoguia (2017), o câncer infantil não está relacionado ao estilo de vida da criança em questão e comumente se desenvolve através de alterações no DNA das células, no começo da vida ou até mesmo antes do nascimento. No que diz respeito ao seu tratamento, "Com algumas exceções, os cânceres infantis tendem a responder melhor a tratamentos como a quimioterapia, pois acredita-se que o organismo da criança tende a receber melhor o tratamento quando se comparado com o adulto.

Segundo o Instituto Nacional de Cancêr (INCA) o número de cancêr no país cresce significamente nas crianças tornando - se uma preocupação constante na saúde. O cancêr é considerado a primeira causa de morte nesse público na faixa etária entre I a 19 anos. Conforme os registros no Sistema de Registro de Cancêr de Base Populacional (RCBP) foram registrados $3 \%$ o qual corresponde a 9.890 casos por tumores pediátrico no país (BRASIL, 2009; SANTOS et al., 2017).

Segundo o Instituto Nacional de Câncer (2008, p. 19), “[...] os tumores diagnosticados na infância são mais de 30 tipos, incluindo os subtipos podem chegar a 5o". Essa doença possui várias especificações e pode ocorrer em qualquer parte do corpo, sendo motivo da causa mortis de muitas crianças. Em específico, seus sintomas podem ser facilmente confundidos com outras doenças comuns na infância, o que pode retardar a procura por um pediatra e, consequentemente, a deteç̧ão precoce da doença. Nesse sentido, 
é fundamental a atenção dos pais a qualquer um dos sintomas (NÚCLEO DE APOIO À CRIANÇA COM CÂNCER, 2007).

Nas últimas quatro décadas, o progresso científico no tratamento do câncer na infância e na adolescência alcançou resultados altamente significativos. Os números mostram que aproximadamente $80 \%$ das crianças e adolescentes diagnosticados com câncer podem ser curados se a doença for identificada precocemente e tratada em centros especializados. Além disso, recebendo o tratamento adequado, grande parte dos pacientes acometidos pela doença apresentarão boa qualidade de vida posteriormente (INCA, 2015).

As preocupações e os impactos voltados ao cancêr em crianças envolvem aspectos fisicos, psicossociais e financeiros sobre a vida do paciente e da família, além dos sentimentos desenvolvidos no decorrer do processo como ansiedade, depressão, medo, angústia resultando em mudança no estilo de vida do paciente e da familia (SANTOS et al., 2017).

A sobrevida dessas crianças está relacionada a inúmeros fatores como, os associado ao próprio paciente entre eles a idade, sexo, tipo de tumor, localização e extensão. Essa sobrevida há décadas retratava à dificuldade ao acesso ao diagnóstico, qualidade e referência de tratamento os quais contribuía para diferenciar as chances de sobrevida. Hodiernamente, sabe - se que devido ao avanço de várias áreas na medicina, avanços tecnológicos para os aparelhos favorecendo o diagnóstico preciso, a estimativa para a cura ultrapassa os $70 \%$ dos casos (BRASIL, 2009).

A respeito do diagnóstico de câncer, ressalta-se que seus anseios são potencializados quando envolvem crianças ou adolescentes. Visto que o câncer infantil representa uma possível cisão com o futuro, o adoecimento de pessoas com pouca idade, principalmente na família, gera um impacto considerado ainda maior, especialmente em relação aos pais quanto ao entendimento de que a doença interrompe o desenvolvimento dos filhos/as e de seus próprios sonhos (CASTRO, 2010). É nesse contexto que, de acordo com Carmo e Souza (2004, p. 13), “[...] os familiares buscam compreender o porquê da doença e encontrar explicações de sua causa, pois nesse momento há uma mistura de sentimentos, como a raiva pela doença, culpa pelo acontecimento, e a negação do diagnóstico".

Diante do diagnóstico, normalmente a família se desorganiza, havendo mudanças em rua rotina e dinâmica, por isso é importante lembrar que a família também faz parte do tratamento e precisa ser acompanhada e assistida (COSTA \& LIMA, 2002).

$\mathrm{O}$ apoio familiar durante o processo da doença de um de seus membros, nesse caso acometido pelo câncer, é vivenciado de forma direta e importante. Franco (2008, p. 358) ressalta que "[...] a família pode ser entendida como um sistema no qual a soma das partes é mais que o todo. Portanto, tudo que afeta um indivíduo afetará a família de forma global”. Nos casos de câncer, para os pais e para a própria criança doente, receber apoio emocional e contar com a participação direta de seus familiares é de grande importância para o enfrentamento da doença.

Neste víeis, observa-se que todas as fases que envolvem o processo do câncer em crianças é doloroso para os responsáveis e para o paciente, e nesse meio tempo se observam os riscos psicossocial junto ao risco biológico pela presença do tumor, tornando-se um desafio devido a vulnerabilidade quanto a doença e o tratamento. Desse modo, é nítido os impactos causados para todos, que pode ser um fator de risco frente as estratégias de 
enfrentamento conhecida como coping, sendo as mais comuns a distração (assistir TV) e ruminação para as crianças, uma vez que, sendo que cada fase desenvolvida nas estratégias dependente umas das outras, se as primeiras forem realizadas com sucesso se torna um facilitador para as demais, promovendo uma melhor aceitação e adaptação futura (CAPRINI, MOTTA, 20I7).

O diagnóstico do câncer é um desafio para a família e para criança, uma vez que, não estão preparados para enfrentar a confirmação. Posteriormente ao diagnóstico, as mudanças começam ao correr em todos os sentidos caracterizado por um período marcado pela negação, rejeição de ambos os lados. Esses sentimentos vão ser mudados a partir da aceitação deles, para isso, envolve o apoio familiar juntamente fortalecido com a assistência da equipe multidiscisplinar (BRUM, 2014).

Brasil (2009) retrata que alguns fatores podem influenciar no tempo gasto do diagnóstico como o tipo de tumor; localização do tumor; idade do paciente; suspeita clínica; extensão da patologia; cuidado ou percepção da doença pelos pais; nível de educação dos pais; distância do centro de tratamento e sistema de cuidado da saúde. Todos esses fatores citados acima podem intervir no diagnóstico do paciente resultando no tardiamento de identificar a patologia, no tratamento adequado e por fim levar a desenvolver serias complicações, às vezes, resultando em óbito.

Segundo Santos et al. (2017) em seu estudo, aponta que o desenvolvimento do câncer nas crianças gera grandes impactos tanto para o paciente quanto para família. A família nesse contexto, principalmente a mãe que acompanha o diagnóstico, o tratamento, constroem sentimentos negativos e positivos como a tristeza, desespero, medo, choque, dor, impotência além de comprometer a vida social, afetiva, comportamental, afastamentos dos familiares e amigos.

Os impactos nas crianças envolvem solidão, isolamento, perca da infância por conta do câncer devido as restrições, desconforto físico e incapacidade, alterações na autoimagem todos esses fatores comprometem a vida da criança além da própria doença (GOMES et al., 2013).

Di Primio et al. (2010) afirmam que, perante o diagnóstico de câncer e da terapêutica estabelecida, toda dinâmica familiar é alterada, pois se faz necessária a adaptação ao ambiente hospitalar, que institui uma dinâmica contrária à de costume. Com a necessidade de os pais comparecerem ao hospital, frequentemente os autores apontam o distanciamento dos seus filhos saudáveis e de suas casas, precisando da ajuda de terceiros para conseguir cuidar dos mesmos.

Sabe-se, dessa forma, que um diagnóstico como o câncer gera inúmeras mudanças no estilo de vida pessoal e familiar, sendo que ter um membro enfermo torna-se fator altamente desestabilizador do equilíbrio familiar. Assim, diante do adoecimento, a família e a criança passam por diversas e significativas mudanças às quais devem se adaptar, tais como, constantes internações, preocupações financeiras, tratamentos agressivos, mudança no cotidiano, ambiente hospitalar, impotência frente ao sofrimento, angústia e principalmente o medo da morte. Estes se configuram como fatores que interferem significativamente na manutenção da qualidade de vida da família afetada (COSTA,2016).

De acordo com Costa, (2016) Essas alterações vivenciadas na rotina da família e do seu papel como referência social e afetuosa da criança vão depender da fase em que a doença 
se encontra e da própria estabilidade do grupo familiar. Além disso, tais mudanças dependem do doente, do diagnóstico do câncer, da viabilidade do tratamento, seus progressos, vantagens e desvantagens e do próprio funcionamento individual e coletivo dos membros desta família. Diante deste cenário, é relevante compreender que cada família possui sua característica e sua própria forma de funcionamento. Assim, embora possam passar por questões comuns, é importante analisar o olhar particular deste grupo de pessoas, levando em consideração a singularidade de cada indivíduo.

Cardoso (2017) confirma que cada família tem sua reação perante o diagnóstico de câncer. A autora traz também as mudanças que a confirmação do câncer implica na dinâmica familiar, entre elas as mudanças financeiras, tendo em vista que, normalmente, um dos responsáveis pela criança abandona seu trabalho para poder se dedicar integralmente a ela. Acrescenta, ainda, mudanças na relação conjugal, pois, devido à preocupação e tensão sobre a situação em que a criança se encontra, os pais deixam em segundo plano o relacionamento do casal; e ainda o distanciamento do filho saudável, sendo esta uma consequência da atenção priorizada exclusivamente ao filho enfermo.

Tão importante quanto o tratamento do câncer, atenção deve ser dada aos aspectos sociais da doença, uma vez que a criança e o adolescente doentes precisam de atenção integral, inseridos no seu contexto familiar. A cura não deve ser baseada apenas na recuperação biológica, mas também no bem-estar e na qualidade de vida do paciente. Assim, não deve faltar ao paciente e sua família, desde o início do tratamento o suporte psicossocial necessário, o que envolve o comprometimento de uma equipe multidisciplinar e a relação com diferentes setores da sociedade, envolvidos no apoio às famílias e à saúde das crianças e jovens (BRASIL, 20II).

Os profissionais de saúde com foco os enfermeiros, devem trabalhar para desconstruir sentimentos e sensações, como incentivar o fortalecimento do vínculo familiar com a escuta em grupos, importância do apoio ao serviço contribuindo para minimização da dor, desespero e abandono (SANTOS et al., 2017).

Como a linguagem utilizada pelo profissional nem sempre é compreendida, faz-se importante salientar que para Sousa et al (2012) as orientações realizadas pelo enfermeiro para as crianças e para seus pais necessitam possuir uma linguagem acessível, precisam ser de fácil compreensão, abrangendo a totalidade desses indivíduos, para que a orientação de fato provoque mudanças no cotidiano das crianças com o objetivo de melhorar sua qualidade de vida

\section{CONCLUSÕES}

Após este estudo pode-se dizer que o câncer é uma doença que acarreta muitas repercussões tanto na vida da pessoa que adoece quanto na dos familiares que acompanham o processo desde o diagnóstico, passando pelo tratamento e recuperação dos casos, requerendo desta forma uma forte atuação da equipe multiprofissional de saúde em relação à avaliação e todo suporte à pessoa e sua família.

O diagnóstico do câncer infantil causa dor, ansiedade e inúmeras variedades de sentimentos. Passar por esse processo é doloroso e envolve muito medo e ansiedade, momentos muito delicados para a criança e sua família. Eles desempenham um papel 
indispensável no tratamento e na luta pela vida. Considerando essas questões e a definição de qualidade de vida, a família e o paciente com câncer, precisa se manter saudável em todos os aspectos para que possa fornecer como a reabilitação do paciente é muito mais do que o aspecto biológico, ela oferece um suporte maior para o paciente.

Portanto, o câncer infantil é assustador. Tem a capacidade de produzir mudanças, distúrbios e manifestações. Não só na vida da criança, mas também na vida de seus familiares, pode causar vários sentimentos e características. É fortes emoções , desespero, incerteza, surpresa e medo. A experiência de uma criança com câncer tem muitos efeitos na vida familiar, alguns deles requerem intimidade, dificuldades financeiras, sacrifício, dor e sofrimento emocional. É como se estivesse passando por uma luta, e os pais questionam a causa dessa doença em suas vidas. O impacto da doença leva as famílias a desenvolverem novas habilidades e tarefas nas rotinas familiares para resolver os conflitos causados pela hospitalização e pelas necessidades físicas, psicológicas e financeiras da doença.

A equipe de enfermagem deve estar preparada para lidar com este tipo de situação bem como compreender todo o processo e o impacto provocado pela doença. Dessa forma pode-se dizer que este estudo serve de subsídio para futuras pesquisas acerca do tema, além de aprimorar e estabelecer cada vez maiso papel dos profissionais de saúde como fundamental para a sobrevivência, a qualidade de vida.

\section{REFERÊNCIAS}

AlveS, K. de M. C., Comassetto, I., Almeida, T. G. de, Trezza, M. C. S. F., Silva, J. M. de O. e, \& Magalhães, A. P. N. de. (2016). A Vivência dos Pais da Criança com Câncer na Condição de Impossibilidade Terapêutica.

BRASIL, Ministério Saúde. Câncer da criança e adolescente no Brasil: dados dos registros de base populacional e de mortalidade. / Instituto Nacional de Câncer. - Rio de Janeiro: INCA, 2008.

BRASIL, Ministério da Saúde. Diagnóstico Precoce do câncer nas crianças e no adolescente. Rio de Janeiro: INCA, 2009. Disponível em:<http://ftp.medicina.ufmg.br/observaped/eixo_oncologiapediatrica/diagnosticoprec o cecanceradolesccrianca\%20institutoronald_23_Io_2013.pdf $>$. Acesso em: 20 maio.2020.

BRUM, Monize Viana. Estudo do impactodo tratamento do câncer infantil nos aspectos emocionais dos cuidadores de crianças com diagnóstico da doença.Revista Científica de Faminas, v.10, n.2, 2014. Disponível em:〈http://www.faminas.edu.br/upload/downloads/20141126163652_658284.pdf.>. Acesso em: 04 maio.2020. 
CAPRINI, Fernanda Rosalem; MOTTA, Alessandra Brunoro. Cancêr Infantil: uma análise do impacto do diagnóstico. Revista Psicologia: Teoria e Prática, v.19, n.2, 2017. Disponível em: $<$ http://pepsic.bvsalud.org/scielo.php?script=sci_arttext\&pid=SI51636872017000200009.>. Acesso em: I4 maio.2020.

CARMO, R. I. S. do; SOUZA, C. de A. Família convivendo com a criança acometida pelo câncer de medula óssea: o stress físico, psíquico e emocional. CBCENF, 7., 2004, Rio de Janeiro. Anais... Rio de Janeiro, 2004, p.I-43.

CARVALHO, M. M. Psico-oncologia: história, características e desafios. Psicologia USP, São Paulo, v. I3, n. I, 2002.

CASTRO, E. H. B. de. A experiência do câncer infantil: repercussões familiares, pessoais e sociais. Rev. Mal-Estar Subj., Fortaleza, v. ıo, n. 3, p. 971-994, set. 2010.

CRISTINNE, Ingrid; DA COSTA, S; AMBROZIO, Leticia; et al. Câncer Infantil: Acompanhamento Psicológico para a Qualidade de Vida Familiar. [s.l.]: , [s.d.]. Disponível em: 〈http://repositorio.aee.edu.br/bitstream/aee/ı132/r/C\%C3\%82NCER\%2oINFANTILACOMPANHAMENTO\%2oPSICOLOGICO....pdf $>$.

CORDOBA, L.G. T. et al. Atuação do pediatra: epidemiologia e diagnóstico precoce do câncer pediátrico. Departamento Científico de Oncologia. Sociedade Brasileira de Pediátria, 2017. Disponível

em:<https://www.sbp.com.br/fileadmin/user_upload/publicacoes/C-Doc-CientificoOncologia-Epidemiol-30-mar-17.pdf.>. Acesso em: 12 mar.2020.

DI PRIMIO, A.O., Schwartz, Eda. Bielemann, V. de L. M., Burille, A., Zillmer, J. O. G. V., \& Feijó, A. M. Rede social e vínculos apoiadores das famílias de crianças com câncer. Texto\& Contexto Enfermagem. 2010.

FRANCO, M. H. P. A família em psico-oncologia. In: CARVALHO, V. A. et al. (Orgs.). Temas em psico-oncologia. São Paulo: Summus, 2008.

FERNANDES, Luana Maria de Souza; SOUZA, Airle Miranda de. Significados do câncer infantil: a morte se ocupando da vida na infância. Psicol. estud., v. 24, 2019. Disponível em: $\langle$ https://www.scielo.br/scielo.php?script=sci_arttext\&pid=SI4I3- 737220190001002II $>$. Acesso em: is mar.2020. 
GOMES, I. P. et al. Do diagnóstico a sobrevivência do cancêr infantil: perspesctivas das crianças. Texto Contexto Enferm, Florianópolis, v.22, n.3, 2013.

GRUPO DE PESQUISA E ASSISTÊNCIA AO CÂNCER INFANTIL (GPACI). São Paulo, 2009.

INSTITUTO NACIONAL DE CÂNCER - INCA. Particularidades do câncer infantil. 2015 .

INSTITUTO ONCOGUIA . (2017). Recuperado de http://www.oncoguia.org.br/conteudo/o-que-ecancer-infantil/2484/I24/

LOURENÇATTO, GabriellaNoberto; MEDEIROS, Tiago Santos;FERMO, Vivian Costa. O diagnostico precocedo câncer na criança e no adolescente: possibilidadese limites.59f. 2010. Universidade Federal de Santa Catarina (Graduação de Enfermagem), Florianópolis, 20ı. Disponível em:<https://repositorio.ufsc.br/xmlui/bitstream/handle/123456789/120739/281752.pdf

NÚCLEO DE APOIO À CRIANÇA COM CÂNCER - NACC. Câncer infantil. Recife, 2007.

PAULA, D.P.S. et al. Câncer infantojuvenil do âmbito familiar: percepções e experiências frente ao diagnóstico. Revista Cuid, v.ıo, n., 2019. Disponível em: <https://revistacuidarte.udes.edu.co/index.php/cuidarte/article/view/570/1049 >. Acesso em: ro maio.2020.

SANTOS, A.F. et al. Vivências de mães com crianças internadas com diagnóstico de cancêr. Universidade Costa Rica, 2017. Disponível em:<https://www.redalyc.org/jatsRepo/448/44854610oo4/html/index.html>. Acesso em: 22 maio. 2020.

SIMONETTI, A. (2013). Manual de Psicologia Hospitalar: O mapa da doença ( $7^{\underline{a}}$ ed., p. 20). São Paulo: Casa do Psicólogo.

VALLE, E. R. M.; RAMALHO, M. A. N. O câncer na criança: a difícil trajetória. In: CARVAlHO, V. A. de et al. Temas em psico-oncologia. São Paulo: Summus, 2008. 